\title{
BUILDINGS' PERFORMANCE SIMULATIONS FOR URBAN SCALE ENERGY DEMAND MODELLING IN THE INTERREG PROJECTS IDEE AND UEB
}

\author{
Massimiliano Condotta ${ }^{1}$, Tiziano Dalla Mora ${ }^{1}$, Giovanni Borga ${ }^{1}$, Fabio Peron ${ }^{1}$ \\ ${ }^{1}$ Università Iuav di Venezia, Venezia, Italy
}

\begin{abstract}
The paper describes methods and results of a procedure for estimating the energy demand of urban areas by calculating energy performace of each individual buildings using a bottom-up approach. The procedure was developed in the framework of the European transnational project IDEE funded by the Interreg IV Italy-Austria programme. The devised methodology uses GIS procedure to analyze the characteristics of the building stock and a series of parametric dynamic energy simulations to calculate the energy demand of individual buildings. Results are compared with the outcomes of a previous research project that used the same city as case study.
\end{abstract}

\section{Introduction}

The work described in this paper is part of the research activities of the European transnational project IDEE (Network of Research Institutions for Planning Efficient Energy Systems in Urban Areas), an initiative funded by the Interreg IV Italy-Austria programme. The aim of the project IDEE is to develop a standard and shared procedure to support public authorities in planning efficient energy systems (for buildings heating and domestic hot water production) and energy saving policies at urban level, district level or at indivudual buildings. The project will also produce a tool for the design and optimization of district heating systems based on centralized renewable energy production or on heat recovered from industrial processes - to be adopted at urban scale. This paper focuses on the bottom-up method, developed inside the project, for figuring the energy demand for heating in a given urban area by calculating the energy demand of each single building. IDEE is an applied research project whose ambition is to build strong relationships with the territory. For this reason, the method is applied and tested in three pilots: the cities of Feltre and Maniago in Italy and the territory of Salzbug in Austria. The application of the method at the city of Feltre has a relevant added value. In fact, the city was a pilot also in the previous Interreg Italy-Austria projet "Urban Energy Web" (UEb). In that project the energy demand of each building was estimated by elaborating gas consumption data provided by energy companies and by processing data about wood stoves uses. This gave to us the possibility to compare the two methods and use the data of UEb to validate the results of the IDEE method. In this paper we desrcibe the pilot that has been done in the city of Feltre. Some comments at the Austrian pilot will be discussed in the final part.

\section{The "City Model" "City sensing" approach}

Conceptually, both the IDEE and the UEb projects are based on the dual "City Model" / "City Sensing" strategy.

When assessing a city, City Model and City Sensing are two specific information clusters that can help design geo-data models dealing with complex urban issues like those related to energy (Condotta and Borga 2018). The City Model cluster contains the information about morphological and physical characteristics of buildings (dimension, height, orientation and construction period). The City Sensing cluster is based on the integration of heterogeneous datasets that are continuously updated by technological systems (e.g. sensors), measurement campaigns, surveys, management and content-enriching processes. The City Sensing provides information on specific traits of a building, such as, the energy consumption, the characteristic energy loss through the walls, or windows, the characteristic energy gain per floor surface, etc..

Combining the data of the City Sensing with the data of the City Model is therefore possible to calculate the energy demand of each specific building of the city. This approach has been used both in the IDEE and in the UEb projects. The differences are the methods used to obtain the two cluster of information.

\section{The UEb method}

In UEb, the City Model and the City Sensing are based on "reconstructed models of the urban environment" (Condotta and Borga 2018). This means that both geometrical dimension of buildings and energy consumption of units are established by measurements of real data and not by estimations.

\section{The definition of City Model in UEb}

The City Model is built up by processing hi-res avionic orthophotos, and avionic laser scanner point cloud datasets. The result is a 3D model of the city that has been managed and elaborated using point cloud processing software to compute the volumes of the buildings. The result of the elaboration has been integrated with other public dataset containing buildings 
data. The main outputs of the elaboration are gross buildings area, height and volume.

\section{The definition of City Sensing in UEb}

The City Sensing in UEb consists of several geocoded datasets of gas consumption, use of biomass and resident information. Regarding the gas consumption, the information comes from the energy agency that gave to us a dataset of gas consumption in $\mathrm{m}^{3} /$ year of each single meter. We can consider this a trustful information; it must nevertheless be considered that many residents integrate the gas heating system with wood-burning stoves. We don't have the data about the quantity of wood used, but we have indication of the residential units that make use of stoves.

\section{Calculation of the energy demand of buildings}

To calculate the energy demand of each specific building, the data of gas consumption of every single meter and of number of stoves have been georeferenced and aggregated for building units.

The $\mathrm{m}^{3}$ of gas are converted considering $1 \mathrm{~m}^{3}=9,65$ $\mathrm{kWh}$. To consider only the energy used for heating, from the total amount of $\mathrm{m}^{3}$ of gas has been deduct a $5 \%$ to exclude gas used for cooking (Condotta, 2017).

To consider also the contribution of the wood stoves, we consider an average value of $18,800 \mathrm{kWh} /$ year for each stove (Condotta, 2017).

\section{The IDEE method}

In UEb, the City Model and City Sensing are based on "reconstructed models of the urban environment" that give important results - because are based on real data but cannot be applied on a large scale. In fact, survey campaigns for City Model construction are time- and money-consuming, while data acquisition from energy companies most of the time involves complex operations (Condotta and Borga 2018).

For this reason, in IDEE, we devised and tested an alternative approach relying on data that can be easily accessed and obtained by any public administration in Italy or any other European country. This approach is no longer based on surveys and measurement of real phenomena, but on "simulated models of the urban environment". This means that the final output - the energy demand of building units - is estimated by a series of simulations.

\section{The definition of City Model in IDEE}

In order to define a replicable methodology in modelling the physical aspects of a city for the entire Italian and Austrian territory, the physical-morphological features of the buildings are firstly obtained by processing the national cadastral database that has homogeneous characteristics for almost all Italian municipalities and also for the Austrian cases.

The City Model in IDEE is based on the classification of building done by using GIS data processing of both alphanumeric and geographical cadastral datasets. Using official cadastral data ensure methodology replicability and re-usability of most processing scripts and algorithms as well as the possibility to extend them to other European countries with few adjustments.

Housing units are one-to-many related to main physical building, so, in order to get total amount of estimated energy consumption for each building, we need first to extract and aggregate detailed information about each housing unit (basically usage and physical parameters) from the alphanumerical raw data and then relate them to the building morphology retrieved by geospatial dataset processing. Alphanumeric dataset processing is basically an optimization/conversion operation aimed at extracting structured data from raw text-format files to get information about the main characteristics of a building such as area, number of floors, cadastral classes and categories, cadastral identification (sheet, parcel, subunit) and street address. As for the geospatial data, the cadastral information system comes instead in a wellknown topographically-correct SHP file (SHP stay for shapefile, a popular geospatial vector data format for geographic information system software) that requires only minor adjustments to fit the Spatial Reference System (SRS) and to perform geoprocessing analysis.

The whole database processing model is structured in three stages: in the first stage we get the most recent cadastral data from the historical series and get the number of floors spanned by each housing unit. In the second stage we group data to get the summary of building parameters filtering out non-heated parts (e.g. garages) generating a geo-referenced dataset with the amount of heated floor area, number of housing units and number of floors per building. This data is used to calculate the total surface area of façades by multiplying façade planar length by the number of floors (considering $3 \mathrm{~m}$ height per level). The last processing stage carries out some more complex geoprocessing procedures to extract base line length of adiabatic surfaces, and the exposure of façades (building orientation). This ending stage puts all data into the destination output database table providing the key to relate them to other datasets. The geometric characteristics of buildings extracted from the City Model are represented in the following Figure 1.

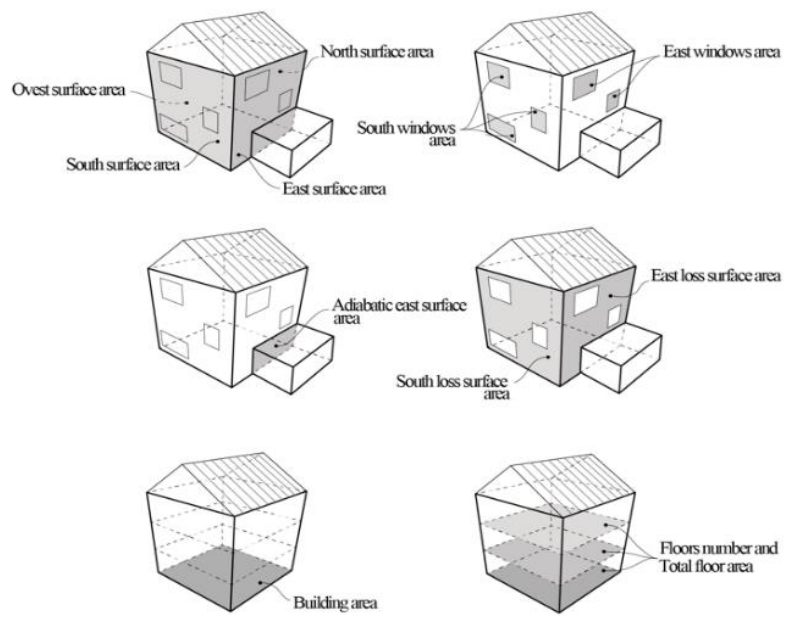

Figure 1: City Model geometric parameters in the IDEE. 


\section{The definition of the City Sensing in IDEE}

The City Sensing in IDEE is defined by a bottom-up approach in order to calculate the typical energy behaviour of building given by the City Model. The dataset is constituded by: the characteristic energy loss per $\mathrm{m}^{2}$ through each single surface represented in fig. 1 (the walls, the basement, the roof or the windows); the characteristic ventilation loss per floors surface; the characteristic internal gain per $\mathrm{m}^{2}$ of floors surface; the characteristic solar gain per $\mathrm{m}^{2}$ of windows surface. These parameters are characterized by walls and windows orientation and by the heigt of the building. For this reason the City Sensing dataset in IDEE is composed by 25 energy loss/gain values in $\mathrm{kWh} / \mathrm{m}^{2} \mathrm{y}$ (Table 1).

Table 1: List of 25 energy loss/gain values $\left(\mathrm{kWh} / \mathrm{m}^{2} \mathrm{y}\right)$ that represent the City Sensing dataset in IDEE.

\begin{tabular}{|c|c|c|}
\hline & Parameterization surface & Variable \\
\hline \multirow{22}{*}{$\begin{array}{c}\text { Transmission } \\
\text { loss: } \mathrm{Q}_{\mathrm{H}, \mathrm{tr}}\end{array}$} & Ground Surface (1 storey buildings) & $\mathrm{Q}_{\mathrm{H}, \mathrm{tr}}\left(\mathrm{S}_{\mathrm{G}}\right) 11$ \\
\hline & Ground Surface (2 storey buildings) & $\mathrm{Q}_{\mathrm{H}, \mathrm{tr}}\left(\mathrm{S}_{\mathrm{G}}\right) 21$ \\
\hline & Ground Surface (3 storeys buildings) & $\mathrm{Q}_{\mathrm{H}, \mathrm{tr}}\left(\mathrm{S}_{\mathrm{G}}\right) 31$ \\
\hline & Roof Surface (1 storey buildings) & $\mathrm{Q}_{\mathrm{H}, \mathrm{tr}}\left(\mathrm{S}_{\mathrm{R}}\right) 11$ \\
\hline & Roof Surface (2 storey buildings) & $\mathrm{Q}_{\mathrm{H}, \mathrm{tr}}\left(\mathrm{S}_{\mathrm{R}}\right) 21$ \\
\hline & Roof Surface (3 storeys buildings) & $\mathrm{Q}_{\mathrm{H}, \mathrm{tr}}\left(\mathrm{S}_{\mathrm{R}}\right) 31$ \\
\hline & East wall Surface (1 storey buildings) & $\mathrm{Q}_{\mathrm{H}, \mathrm{tr}}\left(\mathrm{S}_{\mathrm{E}}\right) 11$ \\
\hline & East wall Surface (2 storey buildings) & $\mathrm{Q}_{\mathrm{H}, \mathrm{tr}}\left(\mathrm{S}_{\mathrm{E}}\right) 21$ \\
\hline & East wall Surface (3 storeys buildings) & $\mathrm{Q}_{\mathrm{H}, \mathrm{tr}}\left(\mathrm{S}_{\mathrm{E}}\right) 31$ \\
\hline & North wall Surface (1 storey buildings) & $\mathrm{Q}_{\mathrm{H}, \mathrm{tr}}\left(\mathrm{S}_{\mathrm{N}}\right) 11$ \\
\hline & North wall Surface (2 storey buildings) & $\mathrm{Q}_{\mathrm{H}, \mathrm{tr}}\left(\mathrm{S}_{\mathrm{N}}\right) 21$ \\
\hline & North wall Surface (3 storey buildings) & $\mathrm{Q}_{\mathrm{H}, \mathrm{tr}}\left(\mathrm{S}_{\mathrm{N}}\right) 31$ \\
\hline & West wall Surface (1 level) & $\mathrm{Q}_{\mathrm{H}, \mathrm{tr}}\left(\mathrm{S}_{\mathrm{W}}\right) 11$ \\
\hline & West wall Surface (2 levels) & $\mathrm{Q}_{\mathrm{H}, \mathrm{tr}}\left(\mathrm{S}_{\mathrm{W}}\right) 21$ \\
\hline & West wall Surface (3 or more levels) & $\mathrm{Q}_{\mathrm{H}, \mathrm{tr}}\left(\mathrm{S}_{\mathrm{W}}\right) 31$ \\
\hline & South wall Surface (1 level) & $\mathrm{Q}_{\mathrm{H}, \mathrm{tr}}\left(\mathrm{S}_{\mathrm{S}}\right) 11$ \\
\hline & South wall Surface (2 levels) & $\mathrm{Q}_{\mathrm{H}, \mathrm{tr}}\left(\mathrm{S}_{\mathrm{S}}\right) 21$ \\
\hline & South wall Surface ( 3 or more levels) & $\mathrm{Q}_{\mathrm{H}, \mathrm{tr}}\left(\mathrm{S}_{\mathrm{S}}\right) 31$ \\
\hline & East windows Surface & $\mathrm{Q}_{\mathrm{H}, \mathrm{tr}}\left(\mathrm{S}_{\mathrm{WE}}\right)$ \\
\hline & Nord windows Surface & $\mathrm{Q}_{\mathrm{H}, \mathrm{tr}}\left(\mathrm{S}_{\mathrm{WN}}\right)$ \\
\hline & West windows Surface & $\mathrm{Q}_{\mathrm{H}, \mathrm{tr}}\left(\mathrm{S}_{\mathrm{WW}}\right)$ \\
\hline & South windows Surface & $\mathrm{Q}_{\mathrm{H}, \mathrm{tr}}\left(\mathrm{S}_{\mathrm{WS}}\right)$ \\
\hline $\begin{array}{c}\text { Ventilation loss: } \\
\mathrm{Q}_{\mathrm{H}, \mathrm{ve}}\end{array}$ & Total floor Surface & $\mathrm{Q}_{\text {in }}\left(\mathrm{S}_{\mathrm{TF}}\right)$ \\
\hline Internal gain: $\mathrm{Q}_{\text {in }}$ & Total floor Surface & $\mathrm{Q}_{\text {in }}\left(\mathrm{S}_{\mathrm{TF}}\right)$ \\
\hline \multirow{4}{*}{ Solar gain: $\mathrm{Q}_{\mathrm{sol}}$} & East windows Surface & $\mathrm{Q}_{\mathrm{sol}}\left(\mathrm{S}_{\mathrm{WE}}\right)$ \\
\hline & Nord windows Surface & $\mathrm{Q}_{\mathrm{sol}}\left(\mathrm{S}_{\mathrm{WN}}\right)$ \\
\hline & West windows Surface & $\mathrm{Q}_{\mathrm{sol}}\left(\mathrm{S}_{\mathrm{WW}}\right)$ \\
\hline & South windows Surface & $\mathrm{Q}_{\text {sol }}\left(\mathrm{S}_{\mathrm{WS}}\right)$ \\
\hline
\end{tabular}

These values are deduced by the dynamic energy simulation of a set of typical buildings.

First of all the urban catalogue is classified according to National Census supplemented by archival research: the building stock is set in use (residential, non-residential), and construction period (before 1919, 1919-1945, 19451970, 1970-1991, 1991-2005, 2005-2013, after 2013).

The thermal behaviour of building envelopes is defined according to each construction period with reference to comprehensive literature review and archival research (Tabula, 2012) (Peron, 2012) (UNI, 2014). As presented in the following Table 2, for each construction period an assumed thermal transmittance (as $\mathrm{U}$-value expressed $\mathrm{W} / \mathrm{m}^{2} \mathrm{~K}$ ) is set for building components: the listed values refer to Feltre case study and describe the performances of the typical building constructed in the mountain north east area of Italy.

Table 2. Thermal transmittance of building components by construction period in $\mathrm{W} / \mathrm{m}^{2} \mathrm{~K}$

\begin{tabular}{|c|c|c|c|c|c|c|}
\hline Code & Period & wall & $p^{2^{5^{2}}}$ & rot & cillo & \\
\hline Y1 & $<1919$ & 2.45 & 2.00 & 1.80 & 1.96 & 5.70 \\
\hline$Y 2$ & $1919 / 1945$ & 1.84 & 2.00 & 1.80 & 2.48 & 4.90 \\
\hline$Y_{3}$ & $1945 / 1970$ & 1.76 & 2.00 & 2.20 & 1.65 & 4.90 \\
\hline Y4 & $1970 / 1990$ & 0.80 & 1.24 & 1.14 & 0.97 & 3.70 \\
\hline Y5 & $1990 / 2005$ & 0.61 & 0.93 & 0.74 & 0.69 & 3.40 \\
\hline Y6 & $2005 / 2013$ & 0.34 & 0.33 & 0.30 & 0.30 & 2.80 \\
\hline Y7 & $2013>$ & 0.27 & 0.30 & 0.22 & 0.28 & 2.20 \\
\hline
\end{tabular}

The model considers the geometry of the thermal zone as $100 \mathrm{~m}^{2}$ of gross heated floor, a WWR (wall to windows ratio) of $10 \%$ for each orientation, an average height of 3 $\mathrm{m}$, and three main types of buildings (L1, L2, L3) set up into four different thermal zones (Ground, Basement, Roof, Medium). Therefore, a single level building corresponds to the thermal zone "Ground", that is different in respect to building with two levels where thermal zones are "Basement" and "Roof". In case of a building with three or more levels the method considers as many "Medium" thermal zone as intermediate levels. In this study, we assumed an average height for each thermal zone of $3 \mathrm{~m}$.

The dynamic simulation software Energy Plus v8.3.0.001 (2016) developed by the US Department of Energy and the graphic interface Design Builder Software Limited v4.7.0.022 (2016) were used for the parametric simulations to calculate primary energy demand. The energy demand for heating, cooling, ventilation, domestic hot water production, lighting and auxiliary services was estimated in accordance with Italian technical specification UNI/TS 11300 series implementing European standards (EC, 2011) (EC, 2007). The weather conditions adopted in the simulation are customed collected in a .epw file with data given by the Belluno weather station, the province capital where the municipality of Feltre is located. The schedule is linked to a residential use with a occupancy density of 2.5 people $/ \mathrm{m}^{2}$ in each thermal zone.

Energy simulations are performed for each type of building according to number of thermal zones (levels) 
and construction period (Figure 2) in order to achieve 21 different buildings types/models and relatives values of energy demand. The reports given by the 21 simulations (three types for each construction period) are then analysed in order to extract aforementioned 25 energy loss/gain values (Table 1 ) in $\mathrm{kWh} / \mathrm{m}^{2} \mathrm{y}$, that are collected in terms of building elememnts, orientation and level for each period.

\section{Calculation of the energy demand of buildings}

The annual heating requirement $\left(\mathrm{Q}_{\mathrm{H}, \mathrm{nd}}\right)$ of buildings is calculated according to the equation (1) implementing European standards (EC, 2011; EC, 2007).

$$
\mathrm{Q}_{\mathrm{H}, \mathrm{nd}}=\left(\mathrm{Q}_{\mathrm{H}, \mathrm{tr}}+\mathrm{Q}_{\mathrm{H}, \mathrm{ve}}\right)-\eta_{\mathrm{H}, \mathrm{gn}}\left(\mathrm{Q}_{\mathrm{in}}+\mathrm{Q}_{\mathrm{sol}}\right)
$$

The calculation considers the monthly effect of the thermal gains - sum of solar $\left(\mathrm{Q}_{\mathrm{sol}}\right)$ and internal gains $\left(\mathrm{Q}_{\text {in }}\right)$ - and losses due to energy transmission $\left(\mathrm{Q}_{\mathrm{H}, \mathrm{tr}}\right)$ and ventilation $\left(\mathrm{Q}_{\mathrm{H}, \mathrm{ve}}\right)$. For the dynamic behavior of the building is taken into account an utilization factor $(\eta \mathrm{H}, \mathrm{gn})$ assumed as 0.80 (experience reveals that the index is usually within the range $0.7-0.9$ depending on thermal mass of the building and on the ratio between losses and gains).

To calculate the energy demand of each individual building of the city the formula (1) is repeated for each building inside a georeferenced database that runs a series of queries. The first set of queries calculates, for each building, the values of $\mathrm{Q}_{\mathrm{H}, \mathrm{r}}, \mathrm{Q}_{\mathrm{H}, \mathrm{ve}}, \mathrm{Q}_{\text {in }}$ and $\mathrm{Q}_{\text {sol. }}$. This calculation is done by matching the City Sensing values with the City Model measures, that is multiplying the characterist values of energy loss/gain (Table 1) of the building by its geometric parametrs (Figure 1).

Then, a second query work out $\mathrm{Q}_{\mathrm{H}, \mathrm{tr}}, \mathrm{Q}_{\mathrm{H}, \mathrm{ve}}, \mathrm{Q}_{\text {in }}$ and $\mathrm{Q}_{\text {sol }}$ according to the formula (1) to get the typical annual energy demand of the building. The result is displayed in Figure 3 .

\section{Comparison of results}

Preliminary remarks and purpose of the comparison

The objective of the comparison here described is to assess the reliability of the results of the IDEE method and determinate if it can be used to estimate the energy demand of buildings and district to support the outline of an optimal energy system setup for urban areas that consider all relevant supply options and individual demand profiles of geolocated objects (buildings).

In the comparison we assume that the results of the UEb method, based on the energy bills analysis, was the benchmark representing the real situation, that is the effective demand of energy of buildings and/or urban areas.

We have performed two different evaluations. The first compare the energy demand of individual buildings (Table 3), the second compare the amount of energy demand of an entire urban area (corresponding to a census zone) (Table 4). The total number of buildings included in the elaborations for the calculation of energy demand is 9231 both in the IDEE and UEb methods. For the first evaluation (Table 3 ) we focused in a small part of the city and we have compared only the buildings that - after an on-site survey - demonstrated to have City Model reliable data. We excluded those buildings with problems in the source database (the problem of the quality of data will be described in the next chapter); this selection has been done because the aim is to perform a preliminary evaluation of the quality of the method and not of the specific application at the case study. In the second comparison, on the contrary, all the buildings

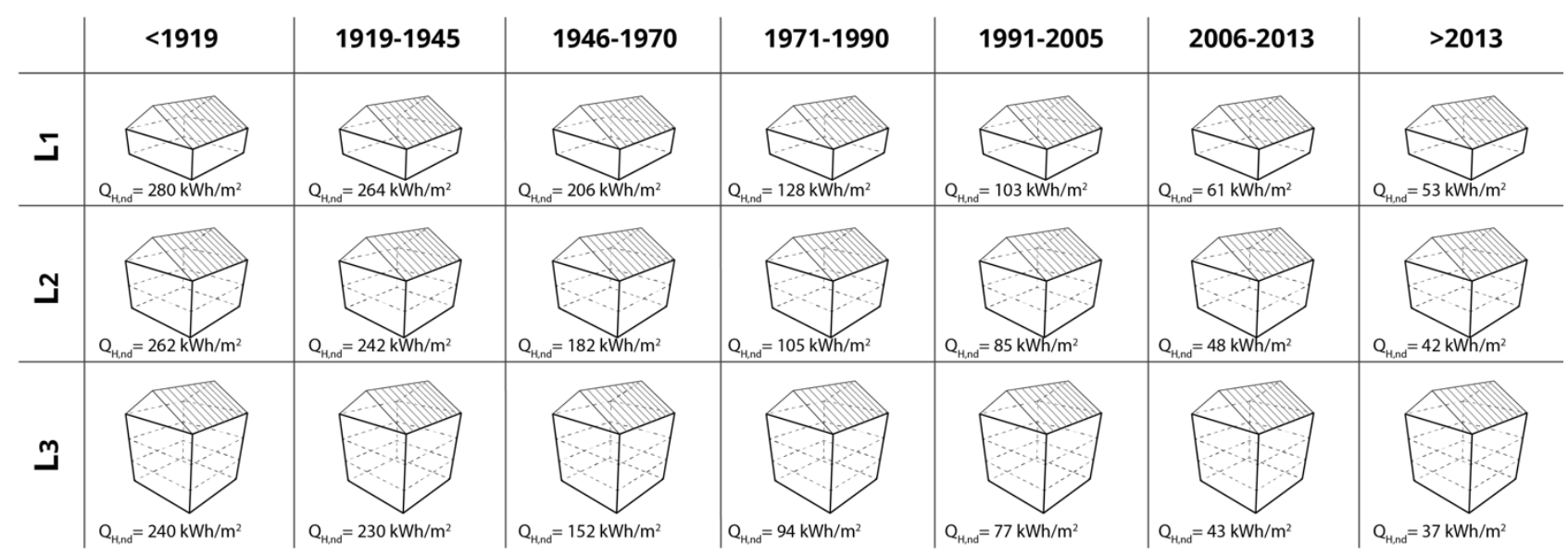

Figure 2: type of buildings simulated to calculate the City Sensing in IDEE with indication of the annual energy demand of the specific type of building calculated with the dynamic energy simulation. 
included in the area of the census zone have been considered; this because the aim is to evaluate if the method can be used to estimate the energy demand of an urban area and, eventually, which corrective parameters can be used. In the comparison of Table 4 are included 12 census zone among a total of 79 . The zones selected cover a total of 1085 buildings and are the ones with the majority of buildings using gas for heating (in fact in some part of the city the gas network is not implemented and these zones have been excluded).

\section{Energy demand of single buildings}

As a first step was analyzed the evaluated energy demand of single buildings. Data in Table 3 present deviations between IDEE method and UEb method. For the major part of the building difference is in the range 15-35\%. Few cases have a better agreement with deviation around 5\%. Only in two cases very high difference are obtained (46\% and 77\%). IDEE method tends to overestimate consumption. This is a consequence of the following assumptions: the habits of the tenants that limit the heating times and the set-point temperature are not considered; the surface used also includes service areas that are not always heated. On the whole it can be stated that given the approximation of the starting data, the agreement is acceptable.

Table 3: Energy demand of individual buildings calculated with the IDEE method and with the UEb method.

\begin{tabular}{|c|c|c|c|c|c|}
\hline 昜 & 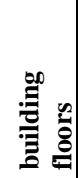 & 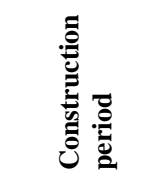 & 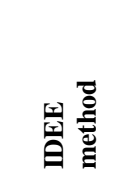 & 옹 & 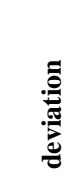 \\
\hline$\left[\mathbf{m}^{2}\right]$ & {$\left[\mathbf{n}^{\circ}\right]$} & & {$[\mathrm{kWh} / \mathrm{y}]$} & {$[\mathrm{kWh} / \mathrm{y}]$} & {$[\%]$} \\
\hline 146 & 2 & $1945 / 1970$ & 56.937 & 68.357 & $-17 \%$ \\
\hline 111 & 2 & $1945 / 1970$ & 40.439 & 29.664 & $36 \%$ \\
\hline 160 & 2 & $1945 / 1970$ & 63.183 & 52.523 & $20 \%$ \\
\hline 513 & 2 & $1970 / 1990$ & 115.737 & 86.144 & $34 \%$ \\
\hline 120 & 2 & $1970 / 1990$ & 31.912 & 25.069 & $27 \%$ \\
\hline 203 & 3 & $1970 / 1990$ & 56.416 & 47.768 & $18 \%$ \\
\hline 207 & 3 & $1945 / 1970$ & 91.380 & 87.932 & $4 \%$ \\
\hline 201 & 3 & $1945 / 1970$ & 96.764 & 66.394 & $46 \%$ \\
\hline 274 & 2 & $1945 / 1970$ & 99.566 & 85.071 & $17 \%$ \\
\hline 233 & 2 & $1945 / 1970$ & 86.209 & 48.745 & $77 \%$ \\
\hline 175 & 2 & $1945 / 1970$ & 65.824 & 52.458 & $25 \%$ \\
\hline 79 & 3 & $1945 / 1970$ & 38.703 & 31.055 & $25 \%$ \\
\hline 36 & 2 & $1945 / 1970$ & 37.356 & 40.658 & $-8 \%$ \\
\hline 261 & 3 & $1970 / 1990$ & 76.215 & 67.141 & $14 \%$ \\
\hline 23 & 3 & $1945 / 1970$ & 53.212 & 55.821 & $-5 \%$ \\
\hline 150 & 3 & $1945 / 1970$ & 65.134 & 62.064 & $5 \%$ \\
\hline 174 & 2 & $1970 / 1990$ & 39.346 & 30.212 & $30 \%$ \\
\hline
\end{tabular}

\section{Energy demand of census zones}

In a second phase the energy consumption of groups of buildings deriving from the census areas was considered. Data in Table 4 present deviations between IDEE method and UEb method. With this procedure they are substantial, exceeding in most cases $100 \%$ and sometimes also $200 \%$. This difference is due to de fact that, considering a block of buildings inside a census zone as a whole, the IDEE method calculate an amount of energy demand, also for the buildings that in reality are unused or that do not have a heating system or that are only partially heated. This last point depends on people behavior that, on its turn, depends on people age, economic situation, family size, etc. To consider this variable should be necessary introduce in the City Sensing another dataset about population. Even if it would be possible to get access at this dataset - that for privacy reason rarely it is diffuse - a specific study in the UEb project demonstrated that there is not a correlation between persons/families' profile (age, economic situation, qualification) and house energy consumption (Condotta 2017). The problem of overestimating the energy demand of a whole census zone is therefore not easy to solve, but a possible solution is to perform some tests in sample areas of the city and derive a corrective factor.

Table 4: Energy demand of some census zones calculated with the IDEE method and with the UEb method.

\begin{tabular}{|c|c|c|c|}
\hline $\begin{array}{c}\text { Buildings } \\
\text { covered }\end{array}$ & IDEE method & $\begin{array}{c}\text { UEb } \\
\text { method }\end{array}$ & deviaton \\
\hline$\left[\mathbf{n}^{\circ}\right]$ & {$[\mathbf{k W h} / \mathbf{y}]$} & {$[\mathbf{k W h} / \mathbf{y}]$} & {$[\%]$} \\
\hline 47 & 2.827 .641 & 1.494 .635 & $89 \%$ \\
\hline 85 & 5.101 .272 & 2.314 .216 & $120 \%$ \\
\hline 177 & 14.148 .914 & 6.323 .028 & $124 \%$ \\
\hline 112 & 13.910 .443 & 5.774 .591 & $141 \%$ \\
\hline 159 & 11.155 .831 & 4.833 .906 & $131 \%$ \\
\hline 54 & 2.831 .677 & 1.785 .778 & $59 \%$ \\
\hline 10 & 299.496 & 172.376 & $74 \%$ \\
\hline 189 & 12.694 .646 & 5.813 .515 & $118 \%$ \\
\hline 118 & 6.692 .644 & 2.855 .727 & $134 \%$ \\
\hline 61 & 7.120 .215 & 3.168 .791 & $125 \%$ \\
\hline 16 & 1.050 .429 & 278.106 & $278 \%$ \\
\hline 57 & 10.539 .585 & 3.249 .756 & $224 \%$ \\
\hline
\end{tabular}




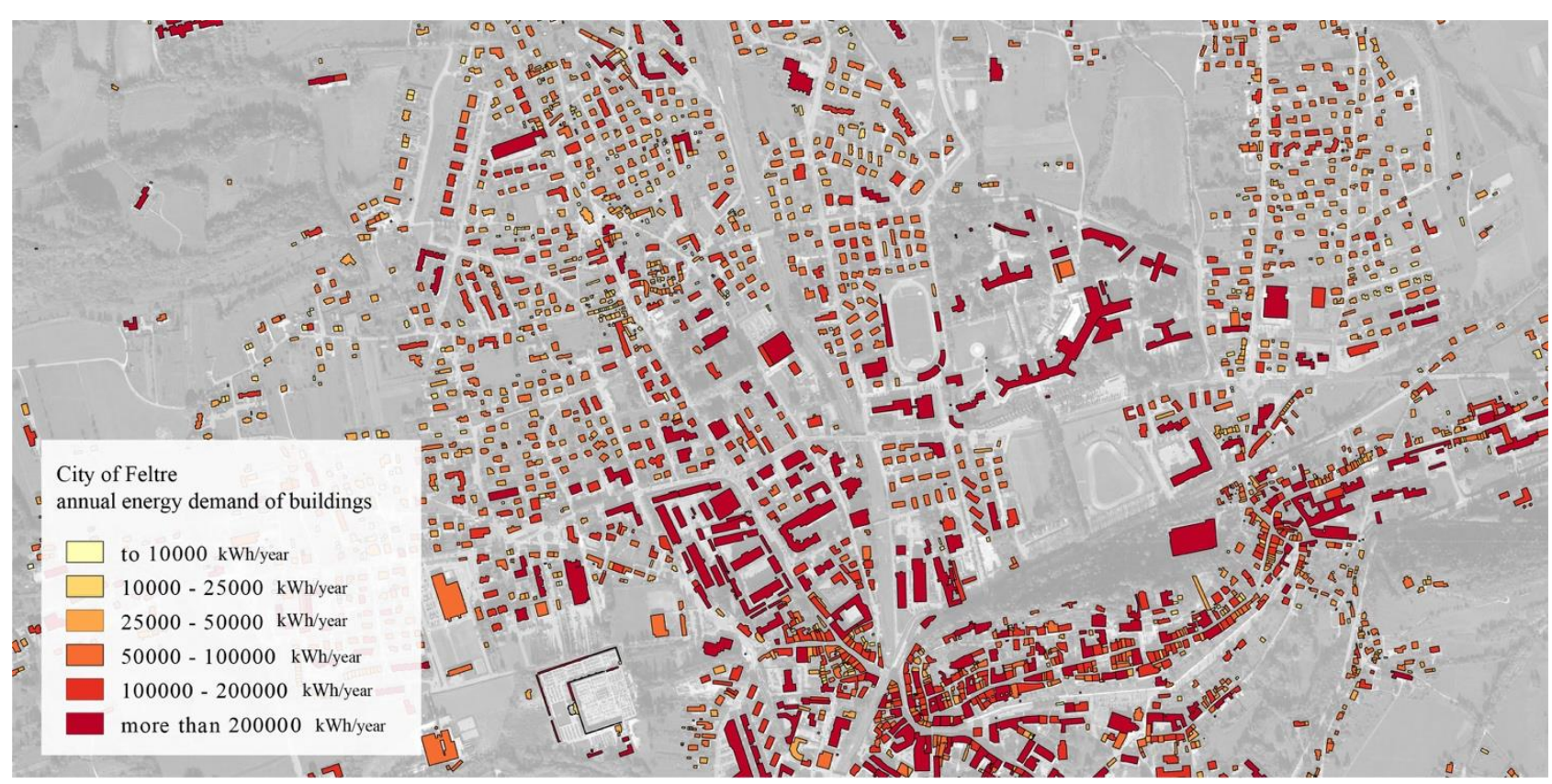

Figure 3: map of the annual energy demand of buildings in the City of Feltre calculated using the IDEE method.

\section{Discussion}

\section{The quality of data in the Italian case study}

The available data for the Italian case study shows several critical issues that basically lower the overall quality of the whole analytical process. Regarding IDEE, firstly, the structure of the Italian national cadastral database is significantly bad-formed since it comes from an outmoded non-SQL database system and makes it difficult to perform standard query operations. In particular, the main issue concerns that elevation data (e.g. floors) are related to single house units in a truly ineffective way because they are written in non-standard free text fields and they must be parsed with complex string processing functions to get quantitative numeric information. Since there is no clear unambiguous data of total height of the main physical building, further calculations must be carried out to compute this value aggregating single units' total floors amount.

Concerning UEb approach, the main issue is that the only available structured data about energy consumption is the gas bills database; other information about different heating systems (wood, gasoline, etc.), different housing usage (e.g. touristic usage) or lack of gas connection are not available. This makes truly difficult to distinguish local lack of data from cases of non-heated building. In UEb, to reduce the error resulting from the lack of alternative heating systems information, an estimated average corrective parameter has been adopted for the whole study area.

The quantitative values obtained using different methodologies in IDEE and UEb makes possible a comparison to understand the deviation between an estimation/modeling approach and a measuring approach. Unfortunately, this comparison is not so easy to carry out because of several inhomogeneities of the resulting datasets. The first one regards the basic difference from the cadastral map layer used in IDEE and the photogrammetric map layer used in UEb; indeed, the first one is made of more building units than the second one that contains a single polygon for several contiguous buildings. The second issue regards that IDEE calculation is housing-units-based whereas UEb is street-address-based. These differences make basically impossible to fully compare the whole dataset at once so that has been adopted a different strategy based on a preliminary manual selection of homogeneous cases to be processed using algorithms.

Finally, for the final comparison summary with census zones aggregated values, only zones with the higher number of gas consumption data has been considered in the calculation.

\section{The quality of data in the Austrian case study}

Unlike city of Feltre, for Seeham - Austria, better quality cadastral data is available, making unnecessary several pre-processing stages in the energy demand estimation. Seeham database indeed provides ready-touse data fields about number of floors and construction year so that we don't need specific queries to process housing units' details and historical cadastral records.

Anyway, IDEE processing schema is based on a step-bystep query tree so it's possible to re-use many of the already developed scripts for Feltre also for Seeham (and even for other case studies in the future); indeed, in IDEE, the processing schema used for Feltre is made of 18 queries and 3 functions and it's been preserved for Seeham version which re-uses 13 queries and 2 functions of the base schema. 


\section{Conclusion}

The output of the UEb method can be seen as a snapshot of the energy behaviour of a city in a specific year. It returns the real energy demand that is influenced by the citizens behavior, by the number of vacant buildings and by the weather conditions of the specific year. Notwithstanding, the information of the UEb method is a good indicator of what is the actual demand of energy. Nevertheless, this data cannot be used to calibrate the design and the optimization of district heating systems. In fact, an integrated urban energy system must be planned to be able to cope with possible increasing of energy demand. For this reason, we have developed and tested also the IDEE method that, on the contrary of $\mathrm{UEb}$, can be seen as the potential energy demand of the city in case all the buildings where used and properly heated. The comparison we have performed can be used to derive a corrective factor to be used to tune the results of the IDEE method.

On the other hand, the test demonstrated that to get better and affordable results with the IDEE method moreover if we are working in Italy - is necessary to make a quality check of data and support this check with surveys in order to get a more reliable City Model cluster.

\section{Acknowledgement}

We want to thank the City of Feltre for the support and the Interrg Italy-Austria program that cofinanced this research project.

\section{References}

Condotta, M. and G. Borga (2018). Urban energy performance monitoring for Smart City decision support environments. TECHNE. Journal of Technology for Architecture and Environment, Special Series Vol. 1. European Pathways For The Smart Cities To Come on behalf of EERA Joint Programme on Smart Cities, 73-80.

Condotta, M., G. Borga, T. Dalla Mora, F. Peron (2018). Urban Scale Simulation Of Energy Demand Of Buildings Based On Parametric Simulation Schemes For Real-Life Applications. Proceedings from BSO 2018, 4th Building Simulation and Optimization Conference. Cambridge (UK) 11-12 September 2018.

Condotta, M. (2017). Urban Energy Web. Il comportamento energetico urbano. Strumenti di analisi e condivisione nel caso studio di Feltre. Maggioli Editore. Santarcangelo di Romagna (Italy).

EC (2007). European Committee for Standardization (CEN). EN 15243:2007. Ventilation for buildings Calculation of room temperatures and of load and energy for buildings with room conditioning systems.

EC (2011). European Committee for Standardization (CEN). EN 15316 (series). Heating systems in buildings - Method for calculation of system energy requirements and system efficiencies.

Peron, F., Romagnoni, P., Righi, A., Turvani, M. (2012). Analisi integrata di scenari di miglioramento dell'efficienza energetica del settore civile e commerciale della regione Veneto. Atti $6^{\circ}$ Congresso AIGE, Ferrara, 11-12 Giugno 2012, pp. 39-44.

TABULA (2012). Typology Approach for Building Stock Energy Assessment, TABULA Project (20092012), http://episcope.eu/ieeproject/tabula/, last access: November 2017.

UNI - Italian Committee for Standardization (2014). Standard UNI TS 11300 Part 1: "Energy performance of buildings: Evaluation of energy need for space heating and cooling". 